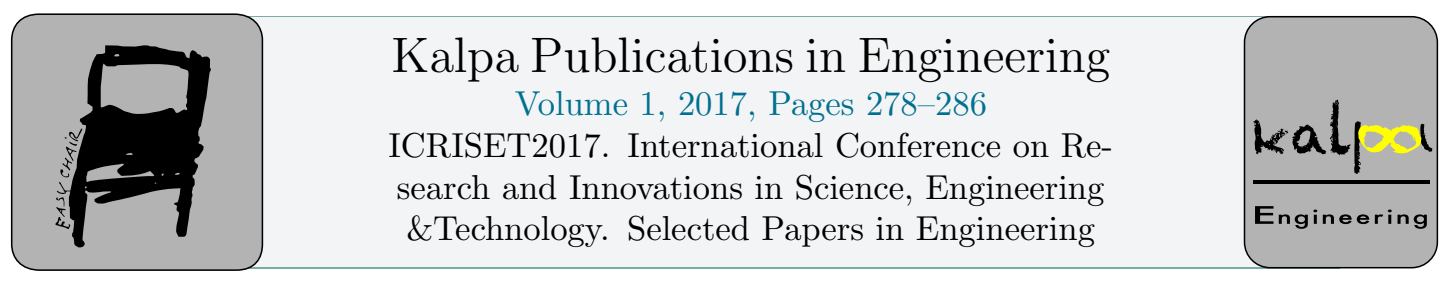

\title{
DSTATCOM for Harmonics Mitigation in 3-Phase 3-Wire System
}

\author{
Odedra Khoda N. ${ }^{1}$, Prof. S.N.Pandya ${ }^{2}$, Dhaval P. Patel ${ }^{3}$ and Maheshwariba \\ P. Zala ${ }^{4}$ \\ 1,2,3,4 Lukhdhirji Engineering College, Morbi \\ odedrakhoda111@gmail.com², saunipandya@gmail.com², dhaval211093@gmai \\ l. com ${ }^{3}$, zal amaheshwariba@gmail.com ${ }^{4}$
}

\begin{abstract}
Distribution systems have been facing serious problems of harmonics load current mainly due to advancement in power electronic based and other non-linear loads. The DSTATCOM has been widely used to mitigate the load current harmonics problems in distribution system. In this paper design and simulation of DSTATCOM with SRF Control Strategy is carried out with 3-phase 3-wire distribution system to mitigate the harmonics load current problem using MATLAB /SIMULIMK software.
\end{abstract}

Keywords-harmonic; DSTATCOM; SRF; Distribution System

\section{Introduction}

Distribution system now days are facing several power quality problems like poor power factor, poor voltage regulation, harmonics current burden, unbalanced loading, neutral current excess etc.[1, 2] Harmonics current is mainly because of use of non-linear nature of load and poor power factor and poor voltage regulation is mainly due to the inductive load and line drop respectively. IEEE-519 standard is proposed to control harmonics current.

The Followings are the effect of harmonics on the various equipments:

1. Damage to the capacitor bank

2. Transformer derating

3. Induction machine crawling

4. Increase of Hysterisis and eddy current losses

5. Interference with communication system

6. Protective devices malfunctioning 


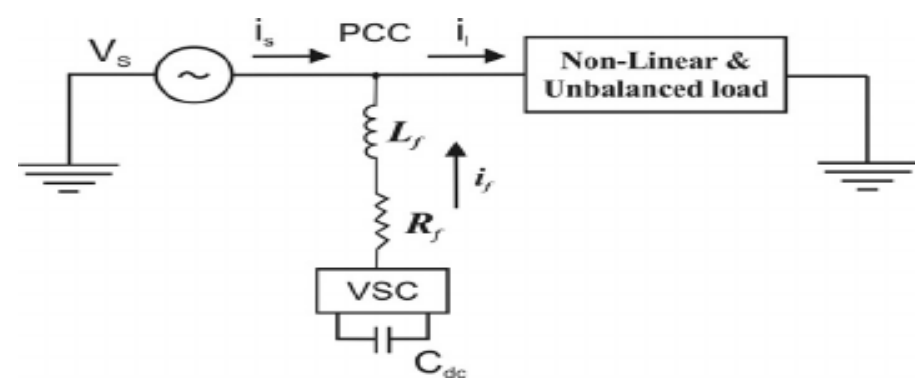

Figure 1: Single Line Diagram of DSTATCOM

Many Custom Power Devices like DVR, UPQC are proposed for mitigating the power quality problems in distribution system.[3] Distribution Static Compensator is shunt connected device whichis abletomitigate load currentbased power quality problems.it injects compensating current such that load current based power quality problems like voltage sag, voltage swell , unbalance loading, poor power factor , poor voltage regulation, harmonics etc. can be mitigated using the DSTATCOM[4, 5].

Many topologies for 3-phase 3-wire and 3-phase 4-wire distribution static compensator has reported in the literature. Some of the 3-phase 3-wire DSTATCOM configurations are three single VSC based, two leg VSC with split capacitor based, 3-leg VSC based DSTATCOM. For control of DSTATCOM many control strategies like SRF theory, p-q theory, Unit template and Hysterisis control, Power balanced theory have proposed in the literature[5-7].

In this paper 3-leg VSC based DSTATCOM with SRF Control Strategy is used to mitigate the harmonics problem due to non-linear load.Figurel shows the single line diagram of the DSTATCOM.

\section{Basic Theory}

Figure 2 shows the generalized diagram of DSTATCOM for 3-phase 3-wire distribution line with the control strategy. DSTATCOM is connected in shunt with the load at the PCC.The DSTATCOM is comprised of 3-leg Voltage Source Inverter with capacitor at the DC link and connected to the distribution line through the interfacing inductor. Capacitor here acts as the energy storage element and inductor is used to reduce the ripple in the current. DSTATCOM can either be used for power quality improvement or for the power flow control in the line. If one wants to use the DSTATCOM for Active Power Flow in the line in that case the energy storage element required is either Battery Energy Storage or the Voltage Source[1].

Load current is sensed and applied to the control strategy and reference source current are generated. Control signal can be generated either by the PWM or by the Hysteresis current control. In the PWM control reference source current is compared with the triangular wave and according to intersection between the two signal the gating pulses are generated. In the Hysteresis current control, the reference source current is compared with the actual source current and according to the Hysteresis band gating signal are generated. DSTATCOM will inject the harmonic current such that it will nullify the effect of load current harmonics on the source side. 


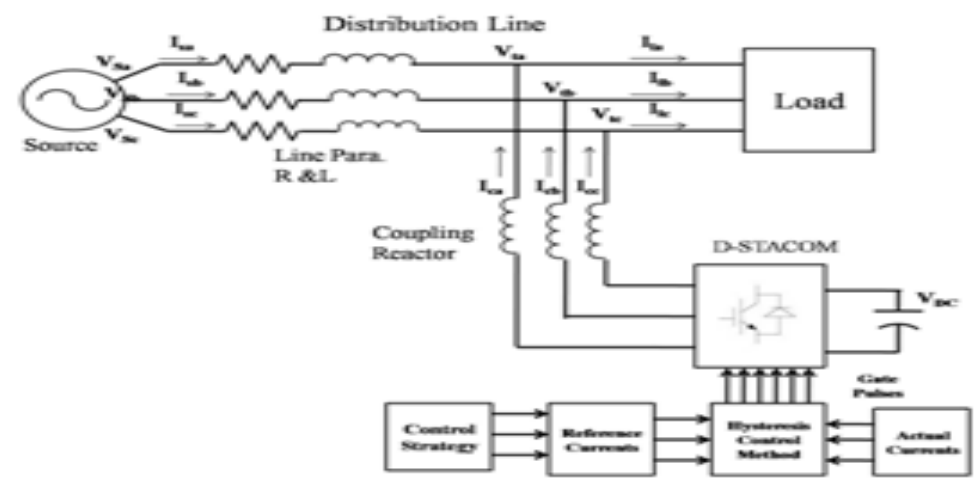

Figure 2: Generalized diagram of DSTATCOM

\subsection{Design of parameter}

IGBT with anti-parallel connected diode is used to the construct the VSC. IGBT is used to construct the VSC because the IGBT is low power device, switching frequency is also medium, there is no problem of second breakdown like BJT, and is comprised theadvantages of both MOSFET and BJT. The anti-parallel connected diode is used to provide the pathfor charging of DC linkcapacitor. The rating of switch can be selected using the following equation (1).

$\mathrm{Vsw}=$ Switch Voltage rating

$$
V_{s w}=V_{D C}+V_{d}
$$

$\mathrm{V}_{\mathrm{dc}}=\mathrm{DC}$ Bus Voltage

$\mathrm{V}_{\mathrm{d}}=10 \%$ overshoot in DC bus Voltage

The current ratings of the IGBT switch can be calculated using the equation given below.

$$
I_{w}=1.25\left(I_{c r}+I_{s p}\right)
$$

$\mathrm{I}_{\mathrm{sw}}=$ Switch Current rating

$\mathrm{I}_{\mathrm{cr}}=$ ripple current

$\mathrm{I}_{\mathrm{sp}}=$ peak current Capacitor

Switch voltage and current rating should be higher than the calculated value so for safety purpose in case of any abnormal condition occurs in the system.

DC bus voltage of the capacitor must be greater than the twice of the phase voltage of the system otherwise the DSTATCOM cannot supply the compensating current to the system. In case of Active Power Flow control using DSTATCOM one need to use either battery energy storage or a voltage source but for only reactive power flow control capacitor alone can be used as energy storage. DC bus voltage can be calculated using the equation (3). 
Where

$\mathrm{V}_{\mathrm{dc}}=$ DC Bus Voltage, $\mathrm{V}_{\mathrm{LL}}=$ Line to Line Voltage of the system, $\mathrm{m}=$ modulation index

$$
V_{D C}=2 \sqrt{\frac{2}{3}} \frac{V_{L L}}{m}
$$

The value of the capacitor depends upon the energy balanced Equation and can be calculated using equation (4).

$$
\frac{1}{2} C_{D C}\left(V_{D C r e f}^{2}-V_{D C}^{2}\right)=3 V_{p h} \text { aIt }
$$

$\mathrm{C}_{\mathrm{dc}}=\mathrm{DC}$ Bus capacitor, $\mathrm{V}_{\mathrm{DCref}}=$ reference $\mathrm{DC}$ bus voltage, $\mathrm{V}_{\mathrm{DC}}=$ minimum value allowed of reference DC bus voltage, $\mathrm{Vph}=$ phase voltage, $\mathrm{a}=$ overloading factor which is taken generally as $1.2, \mathrm{I}=$ current at output of the DSTATCOM, $\mathrm{t}=$ time by which energy should be recovered during transient.

The interfacing inductor is used to smoothing out the compensating current. The ripple is reduced by using the interfacing inductor. The ripple in the current are introduced due to the firing of different switches. If the switching frequency is higher in that case the ripple is much less but switching losses increases to great extent.

The interfacing inductor value is directly proportional to dc bus voltage and inversely proportional to the ripple current and switching frequency as given in equation (5).

$$
L_{f}=\sqrt{3} m V_{D C} / 12 a f_{s} I_{C r p p}
$$

$\mathrm{L}_{\mathrm{f}}=$ interfacing inductor, $\mathrm{m}=$ modulation index and is generally taken as 1 for the most of the DSTATCOM configuration, $\mathrm{V}_{\mathrm{dc}}=\mathrm{DC}$ Bus Voltage, $\mathrm{a}=$ overloading factor which is taken generally as $1.2, \mathrm{I}_{\text {crpp }}=$ ripple current.

\section{Control Strategy}

Many control schemes have been introduced in the literature like SRF, p-q theory, power balanced theory, unit template and Hysterisis current control and most widely used control scheme is Synchronous reference frame theory based. Synchronous Reference Frame theory is also called as SRF, d-q-o theory or Parks transformation. DC bus voltage, load current, and source voltage and source current are sensed and used in this control scheme. 3-phase load current $\mathrm{I}_{\mathrm{a}}, \mathrm{I}_{\mathrm{b}}$, $I_{c}$ are sensed and converted into d-q- 0 form as given in below equation.

$$
\left(\begin{array}{l}
I_{L d} \\
I_{L q} \\
I_{L 0}
\end{array}\right)=\frac{2}{3}\left(\begin{array}{ccc}
\cos (\theta) & \cos \left(\theta-2 \frac{\pi}{3}\right) & \cos \left(\theta+2 \frac{\pi}{3}\right) \\
\sin \theta & \sin \left(\theta-2 \frac{\pi}{3}\right) & \sin \left(\theta+2 \frac{\pi}{3}\right) \\
\frac{1}{2} & \frac{1}{2} & \frac{1}{2}
\end{array}\right)\left(\begin{array}{c}
I_{L a} \\
I_{L b} \\
I_{L c}
\end{array}\right)
$$




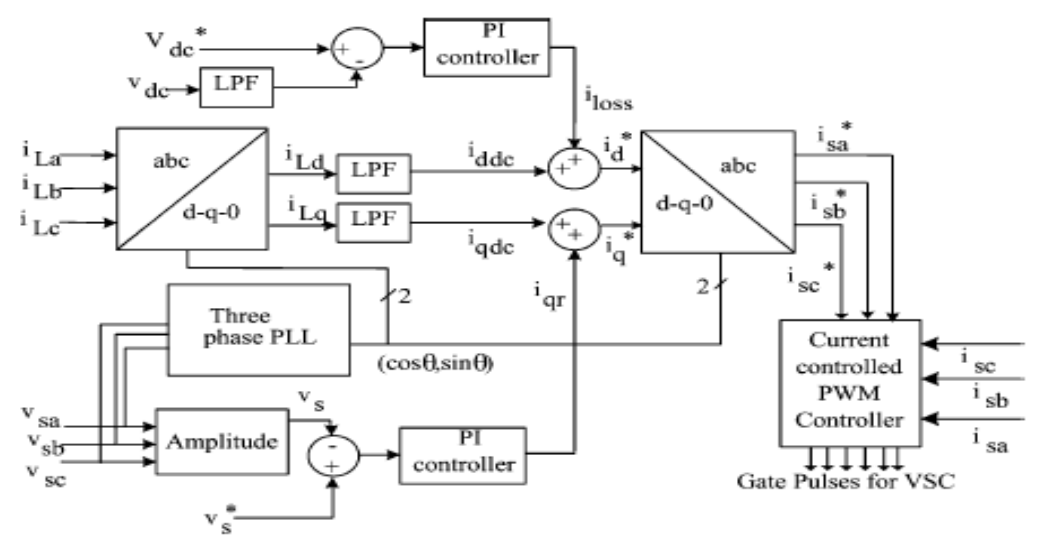

Figure 3: SRF Control Scheme

Reference source current can be obtained using the inverse d-q-0 transformation

$$
\left(\begin{array}{l}
I_{s a}^{*} \\
I_{s b}^{*} \\
I_{s c}^{*}
\end{array}\right)=\left(\begin{array}{ccc}
\cos \theta & \sin \theta & 1 \\
\cos \left(\theta-2 \frac{\pi}{3}\right) & \sin \left(\theta-2 \frac{\pi}{3}\right) & 1 \\
\cos \left(\theta+2 \frac{\pi}{3}\right) & \sin \left(\theta+2 \frac{\pi}{3}\right) & 1
\end{array}\right)\left(\begin{array}{l}
I_{L d}^{*} \\
I_{L q}^{*} \\
I_{0}^{*}
\end{array}\right)
$$

$\mathrm{I}_{\mathrm{Ld}}$ and $\mathrm{I}_{\mathrm{Lq}}$ both contains dc and ac components due to the harmonics present in the system and ac component components are removed using the either low pass filter or the mean block in case of the simulation.

$$
\begin{aligned}
& \mathrm{I}_{\mathrm{ld}}=\mathrm{I}_{\mathrm{ddc}}+\mathrm{I}_{\mathrm{dac}} \\
& \mathrm{I}_{\mathrm{Lq}}=\mathrm{I}_{\mathrm{qdc}}+\mathrm{I}_{\mathrm{qac}}
\end{aligned}
$$

Reference direct axis current is obtained by the adding the $I_{d d c}$ and $I_{\text {loss }}$ where $I_{\text {dloss }}$ component is output of PI controller.

$$
\mathrm{I}_{\mathrm{d}} *=\mathrm{I}_{\mathrm{ddc}}+\mathrm{I}_{\mathrm{dloss}}
$$

$\mathrm{I}_{\mathrm{Lq}}$ depends upon for which operation DSTATCOM is operating either UPF (Unity Power Factor) or ZVR (Zero Voltage Regulation). For UPF operation the reactive power supplied by the source is zero and all the reactive is supplied by the DSTATCOM.

$$
\mathrm{I}_{\mathrm{q}}{ }^{*}=0 \text { (for unity power factor operation) }
$$

For ZVR mode of operation both source and DSTATCOM must supply the reactive power to the load and to maintain the PCC voltage at the nominal value thus keeping voltage regulation zero.

$$
\mathrm{I}_{\mathrm{q}}{ }^{*}=\mathrm{I}_{\mathrm{qdc}}+\mathrm{I}_{\mathrm{qloss}} \text { for ZVR operation }
$$

3-phase PLL (Phase Lock Loop) system is used for synchronizing purpose. Obtained Reference source current are compared with triangular wave in case of PWM control signal generation technique and according to the I the intersection between the reference source current and the 
triangular wave the control signals are generated. In case of Hysteresis current control technique the reference source currents are compared with the actual source current and according to the Hysterisis band the control signals are generated.

\section{Simulation and Results}

Simulation is carried out with the following system data using the matlab/Simulink toolbox. Simulation circuit is shown in Figure 4. source is 3-phase, 415 volt, $50 \mathrm{~Hz}$ is delivering power to the non-linear load which is3-phase bridge with diode rectifier and resistance of $60 \mathrm{ohm}$ at the DC bus through the 3-phase 3-wire distribution system. Load is non-linear so draws discontinuous current from the source but DSTATCOM injects compensating current such that the source

current remains sinusoidal Fig 5 shows the 3-phase source voltage, load current of the phase a $\mathrm{I}_{\mathrm{La}}$, compensating current of the phase a $\mathrm{I}_{\mathrm{Ca}}$, source current of Phase a $\mathrm{I}_{\mathrm{Sa}}$ respectively.

\begin{tabular}{|l|l|l|}
\hline Sr.No. & parameter & Value \\
\hline 1 & source & 415 volt, $50 \mathrm{HZ}$ \\
\hline 2 & load & Universal bridge with $\mathrm{R}=60 \mathrm{ohm}$ \\
\hline 3 & DC bus voltage & 700 volt \\
\hline 4 & Capacitor & $3000 \mu \mathrm{F}$ \\
\hline 5 & Interfacing Inductor & $2.5 \mathrm{mH}$ \\
\hline 6 & $\mathrm{~K}_{\mathrm{pd}}, \mathrm{K}_{\mathrm{id}}$ & $4.8,72.2$ \\
\hline 7 & $\mathrm{~K}_{\mathrm{pk}}, \mathrm{K}_{\mathrm{iq}}$ & $0.0008,0.006$ \\
\hline
\end{tabular}

Table 1: simulation parameter

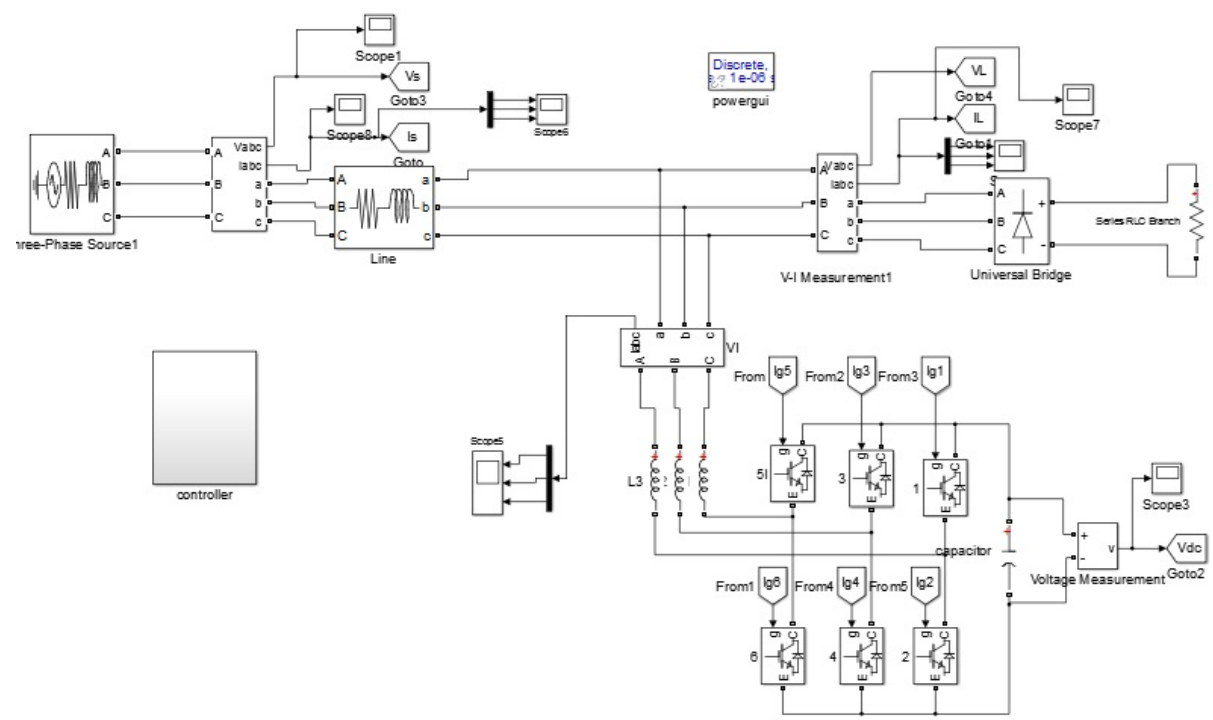

Figure 4: Simulation Diagram 
Source voltage is ideal sinusoidal with 415 volt rms and is balanced condition as shown in Figure 5. Figure 6 shows the load current is nonsinusoidal due non linear behaviour of load which is reflected back on source side so source current is also non sinusoidal without compensation. DSTATCOM injects the compensating harmonic current such that the source current remains sinusoidal even though the load current is non sinusoidal.

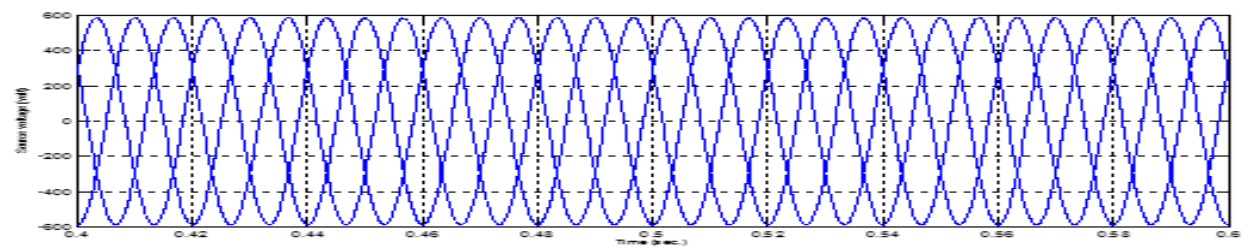

Figure 5: Source Voltage
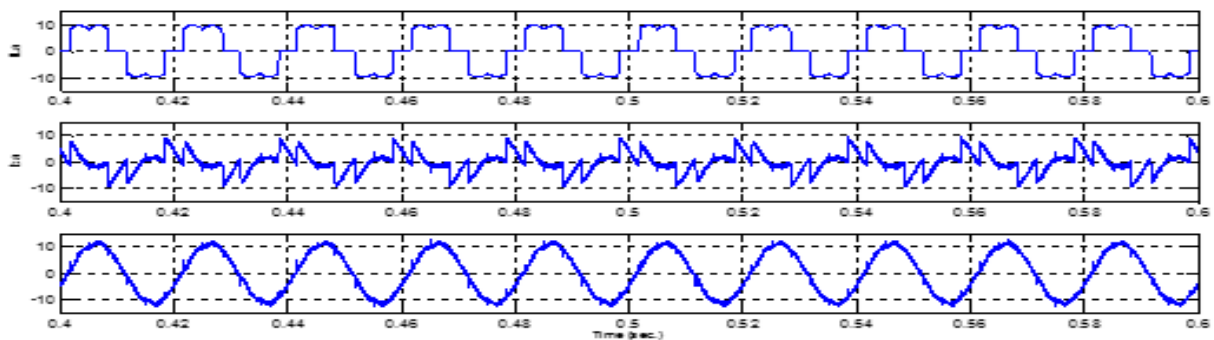

Figure 6: load, compensating and source current

Capacitor is used as energy storage element the DC voltage of it needs to be regulated at the constant value of reference. For that purposed we used the PI controller which maintained the dc bus voltage constant at 700 Volt

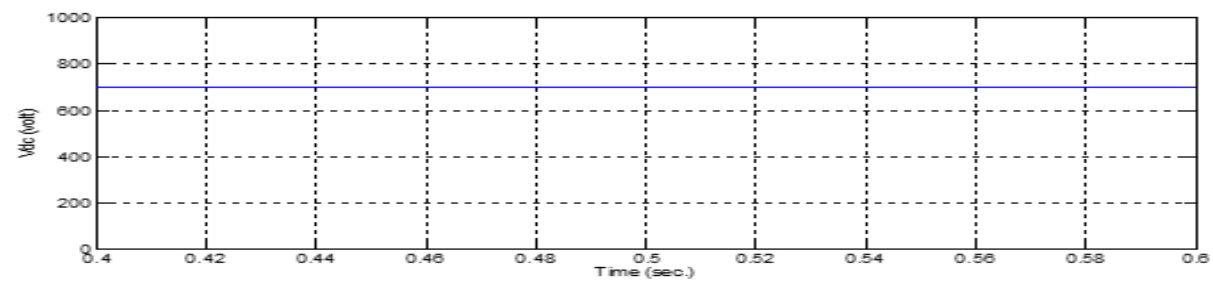

Figure 7 Dc bus voltage

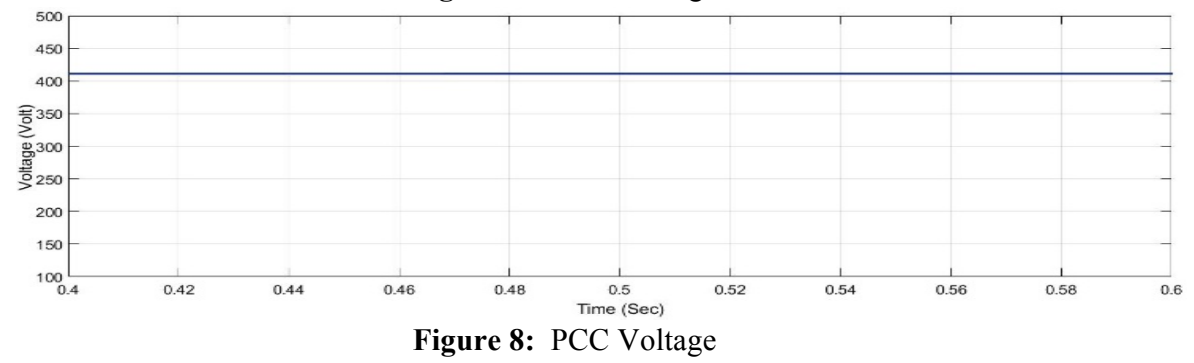




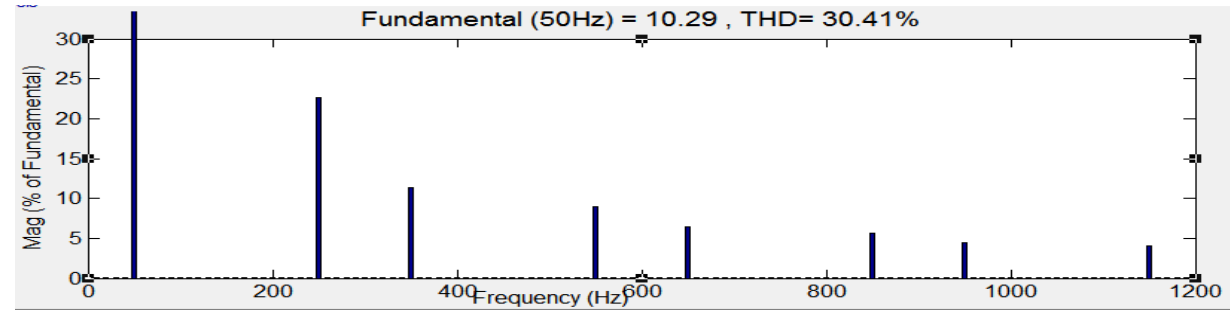

Figure 9: Load current THD

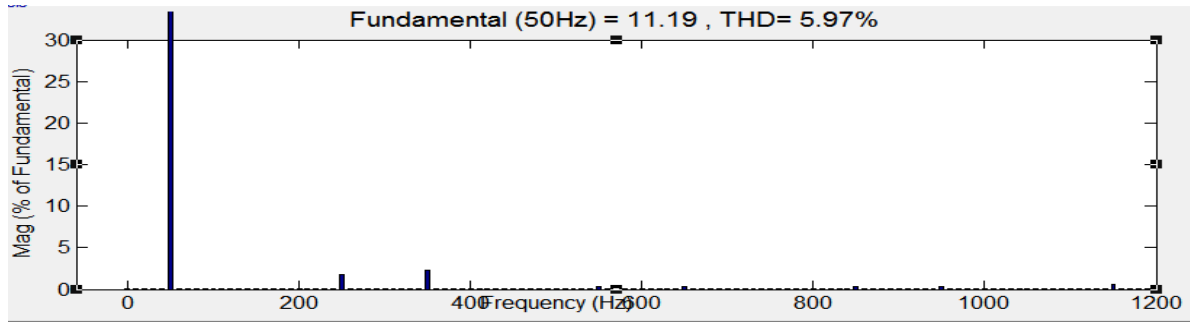

Figure 10: Source current THD

To make the voltage regulation zero another PI controller is used which maintains the load voltage at nominal value by making regulation zero. Figure 7 shows the DC bus voltage whereas the Figure 8 shows the RMS value of the load voltage which indicates thezero regulation. The factor THD is Total Harmonic Distortion and can be evaluated by ratio of Root Mean Square of Harmonic current to Root Mean Square of fundamental current expressed as percentage of fundamental. Figure 9 shows the load current THD which is $30.41 \%$ and Figure 10 shows the source current THD which is $5.97 \%$.

\section{Conclusion}

Due to use of non-linear load the harmonics are introduced which is the main severe problem in distribution system. Simulation results shows that the DSTATCOM using the Synchronous Reference Frame theory is able to maintain the PCC voltage at Reference value by using the PI controller and also maintains the DC bus voltage at the reference value using the PI controller. Simulation results shows that it reduces the THD from $30.41 \%$ to $5.97 \%$.

\section{References}

A. Singh, S. Bhowmick, and K. Shukla, "Load Compensation with DSTATCOM and BESS," in 2012 IEEE 5th India International Conference on Power Electronics (IICPE), 2012, pp. 1-6. 
B. Singh, P. Jayaprakash, D. P. Kothari, A. Chandra, and K. Al Haddad, "Comprehensive study of DSTATCOM configurations," IEEE Transactions on Industrial Informatics, vol. 10, pp. 854-870, 2014.

A. Jain and M. Jain, "Comparison of Star/Delta and Zig/Zag transformer based DSTATCOM for power quality improvement," in Electrical, Electronics and Computer Science (SCEECS), 2016 IEEE Students' Conference on, 2016, pp. 1-6.

B. Singh, P. Jayaprakash, and D. Kothari, "A T-connected transformer and three-leg VSC based DSTATCOM for power quality improvement," IEEE Transactions on Power Electronics, vol. 23, pp. 2710-2718, 2008.

B. Singh and J. Solanki, "A comparison of control algorithms for DSTATCOM," IEEE Transactions on industrial electronics, vol. 56, pp. 2738-2745, 2009.

S. R. Arya, B. Singh, R. Niwas, A. Chandra, and K. Al-Haddad, "Power quality enhancement using DSTATCOM in distributed power generation system," in Power Electronics, Drives and Energy Systems (PEDES), 2014 IEEE International Conference on, 2014, pp. 1-6.

S. Sreejith, U. Bose, K. M. D. S. Vachana, and V. Jyothi, "Application of D-STATCOM as load compensator for power factor correction," in Control, Instrumentation, Communication and Computational Technologies (ICCICCT), 2014 International Conference on, 2014, pp. 595-600. 